\title{
Role of Omega-3 Fatty Acids in Canine Health: A Review
}

\author{
Haneet Kaur*, Ankita Singla, Snehdeep Singh, Sandip Shilwant and Ravneet Kaur
}

Guru Angad Dev Veterinary and Animal Sciences University, Ludhiana-141004, Punjab, India

*Corresponding author

\section{A B S T R A C T}

Ke y w o r d s
Omega-3 fatty
acids, Canine
health, Renal
disease

Fats are regarded as crucial component of a balanced diet in dog as they help to maintain healthy skin coat, cell structure and function, including vision and learning abilities in addition to enhance taste and palatability of food. Omega-3 fatty acids are polyunsaturated fatty acids which are considered as essential fatty acids in dogs because they cannot be synthesized in the body and hence must be provided in the diet. This paper reviews the potential benefits of omega- 3 fatty acids in dogs with osteoarthritis, cardiovascular disorders and renal diseases, atopy, or other inflammatory conditions. In addition, the role of omega fatty acids on neurologic development, behavioral disorders, and reproductive health is summarized along with potential adverse effects like immune function impairment, platelet dysfunction, and altered glucose and lipid metabolism.

\section{Introduction}

Fats and oils are a fundamental part of a balanced diet for dogs. Fats are a concentrated source of energy providing more than double the measure of energy as carbohydrates and proteins do. Fats are comprised of building blocks called fatty acids. Fatty acids are named by their chemical structure and how they are bonded together. There are certain fatty acids that dogs require in their eating regimen in light of the fact that the body can't make them. These are known as essential fatty acids. These essential fatty acids are divided into two groups called the omega-3 and omega-6 fatty acids (Stice, 2019). Fatty acids in both these groups must be given in a specifically adjusted proportion in the daily diet.

Omega-3 FAs are polyunsaturated fatty acids (PUFAs) responsible for numerous cellular functions including the maintenance of the cell membrane structure, fluidity, signaling, and cell-to-cell interaction. They primarily include EPA (eicosapentaenoic acid, C20:5n3), DHA (docosahexaenoic acid, C22:6n-3), and ALA (alpha-linolenic acid, C18:3n-3). 
Both EPA and DHA are found in high concentrations in fish oils, whereas ALA is predominantly present in flaxseeds, canola (rapeseed) oil, soybeans, pumpkin seeds, perilla seed oil, walnuts, and their derivative oils. ALA requires the enzyme delta- 6 and delta-5 desaturases to change over it into EPA and DHA in the body (Bauer, 2011; Fritsch et al., 2010; Roush et al., 2010; Adas et al., 1999; Bibus et al., 1993; Wang et al., 2006). Canines have a constrained capacity to achieve this change (Bauer, 2011; Adas et al., 1999; Bibus et al., 1993; Duda et al., 2009), hence giving preformed EPA and DHA is the most effective approach to raise tissue concentrations of these unsaturated fats.

Omega- 6 fatty acids (also referred to as $\omega-6$ fatty acids or $n-6$ fatty acids) are a family of polyunsaturated fatty acids which mainly include Linoleic acid (LA), Gamma linolenic acid (GLA), Arachidonic acid (AA) and Di homo-gamma-linolenic acids (DGLA). LA is chiefly present in corn, canola, safflower, sunflower oils, whole grain and body fat of poultry, while GLA is abundant in black current seed oil, borage oil and evening primrose oil. Moreover, AA is found in body fat of poultry, lean meat, egg yolks and some fish oils and DGLA is predominantly present in organ meats. Among all, linoleic acid is considered to be the most significant essential fatty acid for dogs.

Although most fats and oils are higher in omega- 6 than omega-3 unsaturated fats, yet it is significant to contain a diet balanced in both. The ratio of omega- 3 to omega- 6 fatty acids and the total quantity of each in the diet is crucial in maintaining wellbeing. The National Research Council (NRC) prescribes a proportion of $2.6: 1$ to $26: 1$ omega- 6 to omega-3 (NRC, 2006). The Association of American Feed Control Officials canine and feline nutrient profiles incorporate a maximum omega- 6 to omega-3 ratio of $30: 1$ (AAFCO, 2016). For comparison, the prescribed intake for humans is $5: 1$ to $10: 1$ omega-6 to omega-3 (Institute of Medicine 2005).

All sources of EFAs are very unstable as they are prone to oxidation and destruction by heat, light, and oxygen. Fish oils (an excellent source of Omega 3 fatty acids) are the quickest to go rancid. Therefore, it becomes necessary to assure that $\operatorname{dog}$ is getting sufficient quantity of EFAs, which can be attained by incorporating an EFA supplement to the diet, using a guaranteed-fresh source packaged in an oxygen-free container.

\section{Role of essential fatty acids}

Fatty acids are considered as essential nutrients in the diet of dogs to ensure optimal health (NRC, 2006; AAFCO, 2016). Essential FAs are required by every mammal for various functions (Torrejon et al., 2007; Calder, 2008; Adhoc Committee on Dog and Cat Nutrition, 2006; Kang and Weylandt, 2008; Zicker et al., 2012) such as:

Maintenance of structure and function of smooth muscle organs (i.e. heart, reproductive system).

Protection and formation of liver cells.

Maintenance of healthy skin structure, functions, coat and strong joint tissues.

Precursors for eicosanoids such as prostaglandins and leukotrienes.

Development of brain and immune system as well as eye (retinal) function in puppies and adult dogs by DHA.

Maintenance of the cutaneous water barrier by Linoleic acid.

Regulation of epidermal proliferation via prostaglandin E-2 by Arachidonic acid.

Insufficient quantities of EFAs in the body severely disrupt critical body functions. Deficiency of EFAs typically leads to development of chronic skin and coat disorders, digestive problems, cardiovascular 
disease, degenerative eye disease, and allergies in dogs and cats. Therefore, EFAs should not be considered as supplemental measures of nutrition, but as crucial components of good health.

\section{Omega 3 fatty acids and dog skin}

Supplementation of dietary fatty acids in dogs and cats is most commonly recommended for pruritic skin diseases related with hypersensitivity reactions, such as flea allergic dermatitis, atopic dermatitis, food associated hypersensitivity and idiopathic pruritus, along with eosinophilic granuloma complex in cats. Dietary EFAs play an important role in the maintenance of water permeability barrier of the skin and normal cell functioning by providing fatty acid precursors of eicosanoids and other significant physiologic mediators (Watson, 1998). The role of linoleic acid (LA) in maintaining the epidermal permeability barrier and being the precursor of prostaglandins in dogs and cats has been shown in various studies (Whelan and Fritsche, 2013). The epidermal water barrier of skin is composed of ceramide in the cell membrane which is derived from the omega- 6 fatty acid (LA). Skin cell cohesion is increased by these lipid components which provide an efficient water barrier to the epidermis. This is the reason that many cases of dry, dull hair coats and scaling, non pruritic skin disorders in dogs show positive effects after supplementation with dietary vegetable oil rich in this fatty acid. Omega-3 fatty acids (ALA) may also work as does LA due to known metabolic competition between these two fatty acid types (Bauer, 2008). Therefore, $\alpha$-linolenic acid can be advantageous in dog skin wellbeing, because of its sparing effect on LA in skin ceramide lipid fractions with less water loss (Bauer, 2011). Supplementation of omega 3 fatty acids in the diet has been found to increase ceramide and fatty acid content of epidermal layer (Popa et al., 2011). Inflammatory response can also be controlled by omega 3 and 6 FAs via the synthesis of less pro-inflammatory mediators from precursors. During traumatic skin conditions, $\omega-6$ FAs (AA) are transformed into PGE-2 and leuckotrienes-4, while $\omega-3$ FAs are changed into PGE-3 and leukotrienes-5, the less pro-inflammatory than their corresponding $\omega-6$ fatty acid isomers. Neutrophil activation is hindered by these newly synthesized $\omega-3$ based mediators resulting in reduction of any allergic or inflammatory condition (Bauer, 2008, 2011). Several clinical studies have reported the efficacy of fatty acids as adjunctive therapy for pruritic dermatoses (Padmanabhan et al., 2017). Dogs on $180 \mathrm{mg}$ EPA and $120 \mathrm{mg}$ DHA supplemented diet from marine oil displayed considerable improvements in pruritus, alopecia, and coat character over time, showing evidence that high-dose marine oil is an efficient anti-inflammatory treatment of canine allergic skin disease and may provide a safe alternative to glucocorticoids for short-term symptom relief. (Logas and Kunkle, 1994). Along with dietary fatty acids, zinc plays an important part in maintaining healthy skin and hair coat (Watson, 1998). Zinc activates the $\Delta-6$ desaturase enzyme required for conversion of $\mathrm{LA}$ to $\mathrm{AA}$ and takes part in both inflammatory and immune mechanisms. Addition of marine fish oil at a dosage of $66 \mathrm{mg} / \mathrm{kg}$ body weight daily for six weeks may be efficient during skin conditions (Watson, 1998). Linoleic acid is found in higher amount in vegetable oils, like sunflower oil, whereas arachidonic acid is present in greater quantities only in animal fats. Dogs with atopic dermatitis may get benefit from supplementation of one teaspoon $(5 \mathrm{~mL})$ of a mixture of vegetable oil and animal fat or fish oil per cup (225 g) of food (Scott et al., 1995). Moreover, the illness may impair the conversion of linoleic acid to the longer-chain ( $\omega-6)$ fatty acids and their 
derivatives, so fatty acid supplemented diet may be advantageous in that condition (Harvey, 1993).

\section{Omega 3 fatty acids and Canine Skeletal Health}

Osteoarthritis has been estimated to influence up to $20 \%$ of dogs > 1 year of age (Johnston, 1997). Dogs of all breeds and ages are affected by the disease. Regular ways to deal with the disease include attempts at prevention, slowing progression, and managing the clinical signs related with $\mathrm{OA}$ which can be achieved with balanced diet, body-weight control, exercise, physical therapy, and anti-inflammatory and analgesic medications (Roush et al., 2010; Henrotin et al., 2005). Although non steroidal antiinflammatory drugs (NSAIDs) are considered as efficient modes of treatment, but have potential negative systemic side effects like gastrointestinal ulceration, liver and kidney damage, and accelerated cartilage degeneration (Henrotin et al., 2005; Hauser et al., 2010). Hence, it becomes urgently important to look for safe options to manage OA. Previous studies in dogs have found the effectiveness of the marine n-3 fatty acids in OA (Roush et al., 2010b; Henrotin et al., 2005; Bauer, 2011; Fritsch et al., 2010b). Studies (Roush et al., 2010a,b; Henrotin et al., 2005; Hauser et al., 2010; Bauer, 2011; Fritsch et al., 2010a,b) have showed that omega-3 fatty acids have helpful impacts in the treatment of rheumatoid arthritis. In addition, the concentration of omega- 3 fatty acids in tissues and cell membranes rise by dietary supplementation with omega-3 fatty acids, bringing about a relative decline in omega- 6 fatty acid concentration, especially that of arachidonic acid. Additionally, studies (Roush et al., 2010a) have revealed that dietary supplementation with fish oil omega-3 fatty acids increases blood concentrations of these unsaturated fats. Furthermore, owners have reported significant improvements in the clinical signs of osteoarthritis, like walking ability after 12 and 24 weeks on supplementation of diet with approximately $0.11 \%$ omega-3 fatty acids and $2.78 \%$ omega6 fatty acids (very high $\omega-6: \omega-3$, control diet) or $3.47 \%$ omega-3 fatty acids and $2.46 \%$ omega- 6 fatty acids (low $\omega-6: \omega-3$, test food) (Roush et al., 2010a). Furthermore, ingestion of fish oil omega-3 fatty acids improves clinical signs in dogs with osteoarthritis (Roush et al., 2010b). Supplementation of fish oil in the diet containing $1.75 \mathrm{~g} \mathrm{EPA} / \mathrm{kg}$ and $2.2 \mathrm{~g} \mathrm{DHA} / \mathrm{kg}$ diet $(\omega-6: \omega-3$ ratio of $3.4: 1)$ does not promote lymphocyte proliferation in dogs (LeBlanc et al., 2007). Moreover, high omega-3 fatty acid revealed better locomotor ability and performance of daily living activities in dogs when the effects of diets containing either $1.47 \%$ omega-3 and $1.86 \%$ omega- 6 fatty acids ( $\omega-6: \omega-3$ ratio of 1.3$)$ or $0.18 \%$ omega-3 and $2.43 \%$ omega- 6 fatty acids ( $\omega-6: \omega-3$ ratio of 13.6$)$ were compared. These impacts might be inferable from the partial replacement of arachidonic acid in cell membranes by EPA and DHA which leads to reduced availability of ARA for conversion in to leukotrienes and prostaglandins (Hall et al., 2006; Hansen et al., 2008; LeBlanc et al., 2008). EPA and DHA produce lesser inflammatory molecules (e.g., prostaglandinE3, leukotrieneB5) with a resultant competitive hindrance of ARA metabolism (Wang et al., 2006). This results in a decrease in anti-inflammatory environment systemically and within the joint.

\section{Omega -3 FA in relation to canine cardiovascular system disorders}

Cardiac diseases affect approximately $11 \%$ of dog and 20\% of feline populations (Hundal, 2020). Nowadays, heart failure is the main cause of death in domestic carnivores (Sagols et al., 2011). Nutrition can be optimally used 
as a medicine for the treatment of cardiac diseases in dogs and cats. Omega -3 FA has many beneficial effects in cardiac diseases as shown in many experiments. Production of TNF and IL-1 are directly reduced by omega$3 \mathrm{FA}$ and its supplementation has been shown to reduce the muscle loss in dogs with $\mathrm{CHF}$ (Freeman, 2010). Supplementation of omega3 FA decrease the production of inflammatory mediators leading to decrease in platelet aggregation and inflammation and increase in vasodilation (Biagi et al., 2004), reduce arrhythmogenesis, reduce plasma triacylglycerols and VLDL leading to inhibition of atherosclerosis. In an experiment conducted by Freeman et al., (1998), supplementation of omega -3 FA showed significant decrease in cachexia score, circulatory TNF, IL-1 and PGE. Supplementation leads to decrease in ventricular premature complexes in dogs with arrhythmogenic ventricular cardiomyopathy (Smith et al., 2007). Concentration of EPA and DHA largely decreases in dogs with heart failure when compared to healthy dogs (Freeman et al., 2006). Omega-3 FA also have positive effects on endothelial function, heart rate, myocardial energy metabolism, immune function and heart rate.

Omega-3 FA (EPA+DHA) can be provided as a dietary supplement and the dose of omega-3 FAs currently recommended for dogs and cats with heart failure is $40 \mathrm{mg} / \mathrm{kg} \mathrm{EPA}+25$ $\mathrm{mg} / \mathrm{kg}$ DHA per day (Freeman., 2010). Supplements are needed to achieve this dose as there are small numbers of commercial pet foods that contain this dose. Most appropriate supplement is fish oil as it is high in omega-3 FA and can be supplemented in either liquid or capsule form. Linseed or flaxseed oil are avoided as dogs and cats are unable to use it due to inefficient conversion. Diet should contain about 80 to $150 \mathrm{mg} / 100 \mathrm{Kcal}$ of omega-3 FA and ratio of EPA:DHA of approximately 1.5:1 (Freeman, 2010).

\section{Omega-3 FA and brain development}

From the last 20 years, there is an increased evidence of the essentiality of n-3 fatty acids in brain development (Heinemann et al., 2005). Diets deficient in omega-3 FA are not optimal for early neural development (Pawlosky et al., 1997). These FA are required for brain development as well as its function. Deficiency can lead to the development of functional abnormalities of neural system. Electroretinogram recorded retinal activity and trainability in puppies improved by feeding bitches food supplemented with n-3 FA during gestation and lactation (Zicker et al., 2012). Omega-3 FA act as neuroprotectors and in animals with epilepsy, they can increase the threshold of seizures (Schlanger et al., 2002). In animals with epilepsy they function by new interneurons formation and increasing transmission through GABAergic receptors (Scorza et al., 2009). Diet enriched with n-3 FA alleviates convulsive symptoms in epileptic dogs (Schlanger et al., 2002). Supplementation of n-3 FA in dogs with drugresistant epilepsy leads to the reduction of about $85 \%$ seizures (Scorza et al., 2009). These also improve memory and cognitive function. Dosage of EPA and DHA recommended by NRC (2006) for neurologic diseases are: $130 \mathrm{mg}$ EPA + DHA per 1,000 kcal of metabolizable energy for pregnant bitch and growing puppy after weaning, whereas $25 \mathrm{mg}$ EPA+ DHA per 1,000 kcal of metabolizable energy for pregnant queen and growing kitten after weaning.

Behavior problems are common in the domestic dog (Canis familiaris) population (Voith et al., 1992; Wells et al., 2000; Bradshaw et al., 2002; Kobelt et al., 2003; Hiby et al., 2004). A usual behavioural problem in dogs is aggression, leading to bite injuries reaching great numbers (Mikkelsen and Lund, 2000; Berg et al., 2005). Lipid 
metabolism is shown to play an essential role in canine aggression which has been shown by hypocholesterolemia in aggressive dogs (Sentürk and Yalçin, 2003). A significantly lower quantity of docosahexanoic acid (22:6 n-3) concentration and a prominently higher omega-6/omega-3 ratio has been reported in German Shepherds dogs with aggressive behaviour in contrast to non-aggressive ones (Re et al., 2008). Serotonergic function in the central nervous system is greatly affected by omega-3 fatty acid status in the rat (DeMar et al., 2006) and in humans (Hallahan and Garland, 2004). Higher docosahexanoic acid levels increase the concentrations of cerebrospinal fluid 5-hydroxyindole-aceticacid, which is the main breakdown product of serotonin metabolism (Hibbeln et al., 1997). In addition, decreased serotonin content has been reported with omega-3 fatty acid deficient diet in rat (Olsson et al., 1998). Therefore, serotonergic dysfunction may be regarded as one mechanism relating low omega-3 fatty acids and aggressiveness. A combination of omega-3 fatty acids, magnesium and zinc has been reported to improve some of the behavioral disorders in dogs with common behavior problems (Niyyat et al., 2018).

\section{Omega 3 FA and reproductive health}

Nowadays, the reproductive failure in the canine species is one of the principle concern of breeders and practitioners, who look for specific treatments to deal with it. As indicated by the literature, poor sperm concentration and/or function are considered as the major constraining factors of breeding programs. Along these lines, several investigators examined various protocols to improve semen quality, in both human and veterinary medicine, supplementing a certain daily intake of micronutrients (Surai et al., 2000; Rooke et al., 2001; Wathes et al., 2007; Safarinejad et al., 2012). Little data is accessible for dogs (Domosławska et al., 2015; Kirchhoff et al., 2017). Several human and animal clinical research studies recommend that, fish-derived n-3 polyunsaturated unsaturated fats (PUFA) can have a beneficial effect on sperm motility and fertility (Surai et al., 2000; Rooke et al., 2001; Wathes et al., 2007; Safarinejad et al., 2012; Mitre et al., 2004). In addition, few authors recommended that the n-6:n-3 ratio of spermatozoa is altered by supplementation of n-3 PUFA enriched diet, further improving sperm motility (Mitre et al., 2004). Diet enriched with n-3 PUFA may enhance sperm functions, by altering membrane properties, along with reducing spermatozoa lipidic peroxidation (Liu et al., 2016). Other studies demonstrated that spermatozoa fatty acid (FA) profile gets modified by n-3 PUFA diet (Mitre et al., 2004; Castellano et al., 2010), which promote the susceptibility of membrane PUFA to lipid peroxidation (Marin-Guzman et al., 1997; Cerolini et al., 2000), therefore alters membrane integrity and function, which improves sperm motility and fertility (Cerolini et al., 2000; Yeste et al., 2011).

\section{Omega-3 FA and Renal health}

Renal diseases especially renal failure is not uncommon in dogs and important medical management is dietary modification. There is reduction in renal function with low plasma PUFA level and higher plasma n-3 FA reduces the risk of developing renal insufficiency (Brown et al., 1998). Omega-3 FA has been found to slow the progression of kidney disease in dogs and reduce glomerular capillary hypertension (Asif, 2015). These reduce kidney inflammation due to its antiinflammatory effect and improve blood flow to the kidneys. Progressive canine nephropathies reduced with dietary n-3 FA supplementation and maintain the GFR (glomerular filtration rate) and thereby 
preserve renal structure (Brown et al., 1998). Rise in creatinine level become slowly on n-3 FA supplementation and thereby improve serum albumin levels, proteinuria and lead to reduction in cholesterol and triglyceride levels in serum. Dietary n-3 FA supplementation in renal insufficiency dogs lead to significant reduction in BUN and triglycerides (Brown et al., 1998). A study conducted by Valle et al., (2015) showed significant increase in GFR and decrease in creatinine level after supplementation of renal feed with omega-3 and antioxidants. These also prevent the progression of chronic renal failure (CRF) due to its action on the abnormalities (lipid and immune) that are secondary to CRF. Dosage of EPA and DHA recommended as adjunctive dietary treatment for kidney diseases is $140\left(\mathrm{mg} / \mathrm{kg}^{0.75}\right)$ and approximate dose for $10 \mathrm{~kg} \mathrm{dog}$ is 790mg (Bauer, 2011).

\section{Potential adverse effects of omega-3 fatty acids in Dogs}

Excess doses of omega-3 fatty acids may be related with immune function impairment, platelet dysfunction, and altered glucose and lipid metabolism, based on the review of literature (Hall, 1996; Nabavi et al., 2015). Vitamin E can be added or supplemented in diets enriched with omega fatty acids to prevent or reduce lipid peroxidation and to avoid vitamin E deficiency. Furthermore, there are chances of omega fatty acid-drug interactions. Simultaneous administration of the NSAIDs caprofen or the antiplatelet medication clopidogrel and omega-3 fatty acids may have a negative effect on hemostasis (Lenox and Bauer, 2013). Consideration of individual animal is important prior to omega-3 fatty acid treatment because animals with less platelet counts may not be fit for supplementation. All animals fed diet rich in omega- 3 fatty acids must be observed for possible harmful effects.
In conclusions, omega-3 fatty acids have many beneficial effects on the overall health of canines. They play an important role in animals with osteoarthritis, atopy, or other inflammatory conditions. They are advantageous for neurologic development and can improve skin and coat. In dogs, diet enriched with fish oil help to maintain renal function by increasing the efficacy of renal feed in CKD dogs, as well as prevent cardiovascular disorders. Supplementation of EPA and DHA @ $30 \mathrm{mg} / \mathrm{kg}^{0.75} \mathrm{BW}$ is recommended in the diet of healthy dogs. Nevertheless, more research is needed to firmly establish the amount of and the type of omega fatty acids, as well as the $\omega-6: \omega-3$ fatty acid ratio required for the treatment of various diseases in dogs. Once these studies become available, refinements in the current recommendations or the establishment of recommended doses for clinical veterinary applications can be implemented.

\section{References}

Ad Hoc Committee on Dog and Cat Nutrition, National Research Council. (2006). Fats and fatty acids. In: Nutrient requirements of dogs and cats. The National Academies Press, Washington, D.C. Pp 81-110.

Adas, F., Berthou, F., Salaun, J.P., Dreano, Y. and Amet, Y. (1999). Interspecies variations in fatty acid hydroxylations involving cytochromes P450 2E1 and 4A. Toxicology Letters 110: 43-55.

Asif, M. (2015). The impact of dietary fat and polyunsaturated fatty acids on chronic renal diseases. Current science perspectives 1(2): 51-61.

Association of American Feed Control Officials. (2016). 2016 Official Publication. Oxford, IN: Association of American Food Control Officials Inc.

Bauer, J.E. (2008). Essential fatty acid metabolism in dogs and cats. R. Bras. Zootec. 37: 20-27.

Bauer, J.E. (2011). Therapeutic use of fish oils in companion animals. J. Amer. Vet. Med. 
Assoc. 239: 1441-1451.

Biagi, G., Mordenti, A.L., Cocchi, M. and Mordenti, A. (2004). The role of dietary omega-3 and omega- 6 essential fatty acids in the nutrition of dogs and cats: A review. Prog. Nutr. 6: 97-107.

Bibus, D.M. and Stitt, P.A. (1993). Metabolism of alpha-linolenic acid from flaxseed in dogs. World Rev. Nutr. Diet. 83: 186-198.

Bradshaw, J.W.S., McPherson, J.A., Casey, R.A. and Larter, I.S. (2002). Aetiology of separation related behavior in domestic dogs. Vet. Rec. 151: 43-46.

Brown, S.A., Brown, C.A., Crowell, W.A., Barsanti, J.A., Allen, T., Cowell, C. and Finco D.R. (1998). Beneficial effects of chronic administration of dietary $\omega-3$ polyunsaturated fattyacids in dogs with renal insufficiency. J. Lab. Clin. Med. 131(5): 447-55.

Brown, S.A., Finco, D.R. and Brown, C.A. (1998). Is there a role for dietary polyunsaturated fatty acid supplementation in canine renal disease. J. Nutr. 128: 2765S2767 S.

Calder, P.C. (2008). The relationship between the fatty acid composition of immune cells and their functions. Prostaglandins Leukot. Essent. Fatty Acids 79: 101-108.

Castellano, C.A., Audet, I., Bailey, J.L., Laforest, J.P. and Matte, J.J. (2010). Dietary omega-3 fatty acids (fish oils) have limited effects on boar semen stored at 17 degrees $\mathrm{C}$ or cryopreserved. Theriogenology 74: 1482 1490.

Cerolini, S., Maldjian, A., Surai, P. and Noble, R. (2000). Viability, susceptibility to peroxidation and fatty acid composition of boar semen during liquid storage. Anim. Reprod. Sci. 58: 99-111.

DeMar, J.C., Ma, K., Bell, J.M., Igarashi, M., Greenstein, D. and Rapoport, S.I. (2006). One generation of $n-3$ polyunsaturated fatty acid deprivation increases depression and aggression test scores in rats. J. Lip. Res. 47: 172-180.

Domosławska, A., Zdunczyk, S., Nizanski,W., Jurczak, A. and Janowski, T. (2015). Effect of selenium and vitamin $\mathrm{E}$ supplementation on semen quality in dogs with lowered fertilitity. B. Vet. I. Pulawy 59: 85-90.
Duda, M.K., O'Shea, K.M. and Tintinu, A. (2009). Fish oil, but not flaxseed oil, decreases inflammation and prevents pressure overload-induced cardiac dysfunction. Cardiovasc. Res. 81: 319-327.

Freeman, L.M. (2010). Beneficial effects of omega-3 fatty acids in cardiovascular disease. J. Small Anim. Pract. 51: 462-470.

Freeman, L.M., Rush, J.E. and Kehayias, J.J. (1998). Nutritional alterations and the effect of fish oil supplementation in dogs with heart failure. J. Vet. Intern. Med. 12: 440448.

Freeman, L.M., Rush, J.E. and Markwell, P.J. (2006). Effects of dietary modification in dogs with early chronic valvular disease. J. Vet. Intern. Med. 20: 1116-1126.

Fritsch, D.A., Allen, T.A. and Dodd, C.E. (2010). A multicenter study of the effect of dietary supplementation with fish oil omega-3 fatty acids on carprofen dosage in dogs with osteoarthritis. J. Amer. Vet. Med. Assoc. 236: 535-539.

Fritsch, D.A., Allen, T.A. and Dodd, C.E. (2010). Dose-titration effects of fish oil in osteoarthritic dogs. J. Vet. Intern. Med. 24: 1020-1026.

Hall, J.A. (1996). Potential adverse effects of long- term consumption of (n- 3) fatty acids. Comp. Cont. Educ. Pract. 18: 879-95.

Hall, J.A., Picton, R.A., Skinner, M.M., Jewell, D.E. and Wander, R.C. (2006). The (n-3) fatty acid dose, independent of the (n-6) to (n-3) fatty acid ratio, affects the plasma fatty acid profile of normal dogs. J. Nutr. 136: 2338-2344.

Hallahan, B. and Garland, M.R. (2004). Essential fatty acids and their role in the treatment of

Hansen, R.A., Harris, M.A. and Pluhar, G.E. (2008). Fish oil decreases matrix metalloproteinases in knee synovial of dogs with inflammatory joint disease. J. Nutr. Biochem. 19: 101-108.

Harvey, R.G. (1993). A comparison of evening primrose oil and sunflower oil for the management of papulocrustous dermatitis in cats. Vet. Rec. 133: 571-73.

Hauser, R.A. (2010). The accelerstion of articular cartilage degeneration in osteoarthritis by non steroidal anti-inflammatory drugs. Journal of Prolotherapy 2: 305-322. 
Heinemann, K.M., Waldron, M.K., Bigley, K.E., Lees, G.E. and Bauer, J.E. (2005). Long chain (n-3) polyunsaturated fatty acids are more efficient than linoleic acid in improving electroretinogram responses of puppies exposed during gestation, lactation, and weaning. J. Nutr. 135: 1960-1966.

Henrotin, Y., Sanchez, C. and Balligand, M. (2005). Pharmaceutical and nutraceutical management of canine osteoarthritis: present and future perspectives. Vet. J. 170: 113-123.

Hibbeln, J.R., Umhau, J.C., George, D.T. and Salem, N. Jr. (1997). Do plasma polyunsaturates predict hostility and depression? World Rev. Nutr. Diet. 82: 175-186.

Hiby, E.F., Rooney, N.J. and Bradshaw, J.W.S. (2004). Dog training methods: their use, effectiveness and interaction with behavior and welfare. Anim. Welfare 13: 63-69.

Hundal, J.S. (2020). Role of omega-3 FA in canine health. Lead paper in ISACPCON2020, $17^{\text {th }}$ National Congress on Canine Practice and National Symposium on "Maximizing Diagnosis, Therapy and Welfare in Canine Practice in Current Scenario" on 21-23 Jan 2020. Pp 107-109.

impulsivity disorders. Prostaglandins Leukot. Essent. Fatty Acids 71: 211-216.

Institute of Medicine. (2005). Dietary Reference Intakes for Energy, Carbohydrate, Fiber, Fat, Fatty Acids, Cholesterol, Protein, and Amino Acids (Macronutrients). Washington, D.C.: National Academy Press.

Johnston, S.A. (1997). Osteoarthritis. Vet. Clin. North Am. Small Anim. Pract. 27: 699723.

Kang, J.X. and Weylandt, K.H. (2008). Modulation of inflammatory cytokines by omega- 3 fatty acids. Subcell. Biochem. 49: 133-43.

Kirchhoff, K.T., Failing, K. and Goericke-Pesch, S. (2017). Effect of dietary vitamin E and selenium supplementation on semen quality in Cairn Terriers with normospermia. Reprod. Domest. Anim. 52: 945-952.

Kobelt, A.J., Hemsworth, P.H., Barnett, J.L. and Coleman, G.J. (2003). A survey of dog ownership in suburban Australian conditions and behavior problems. Appl. Anim. Behav. Sci. 82: 137-148.

LeBlanc, C.J., Dietrich, M.A. and Horohov, D.W. (2007). Effects of dietary fish oil and vitamin $\mathrm{E}$ supplementation on canine lymphocyte proliferation evaluated using a flow cytometric technique. Vet. Immunol. Immunop. 119(3-4):180-188.

LeBlanc, C.J., Horohov, D.W. and Bauer, J.E. (2008). Effects of dietary supplementation with fish oil on in vivo production of inflammatory mediators in clinically normal dogs. Am. J. Vet. Res. 69(4): 486493.

Lenox, C.E. and Bauer, J.E. (2013). Potential adverse effects of omega-3 fatty acids in dogs and cats. J. Vet. Intern. Med. 27(2): 217-226.

Liu, Q., Zhou, Y.F., Duan, R.J., Wei, H.K., Peng, J. and Jiang, S.W. (2016). Dietary n-6:n-3 ratio and Vitamin $\mathrm{E}$ improve motility characteristics in association with membrane properties of boar spermatozoa. J. Androl. 18: 1-7.

Logas, D. and Kunkle, G.A. (1994). Doubleblinded crossover study with marine oil supplementation containing high-dose icosapentaenoic acid for the treatment of canine pruritic skin disease. Vet. Dermatol. 5(3): 99-104.

Marin-Guzman, J., Mahan, D., Chung, Y., Pate, J. and Pope, W. (1997). Effects of dietary selenium and Vitamin $\mathrm{E}$ on boar performance and tissue responses, semen quality, and subsequent fertilization rates in mature gilts. J. Anim. Sci. 75: 2994-3003.

Mikkelsen, J. and Lund, J.D. (2000). Euthanasia of dogs due to behavioural problems: an epidemiological study of euthanasia of dogs in Denmark, with a special focus on problems of aggression. Eur. J. Companion Anim. Pract. 10: 143-150.

Mitre, R., Cheminade, C., Allaume, P., Legrand, P. and Legrand, A.B. (2004). Oral intake of shark liver oil modifies lipid composition and improves motility and velocity of boar sperm. Theriogenology 62: 1557-1566.

Moreau, M., Troncy, E. and Del Castillo, J.R.E. (2013). Effects of feeding a high omega-3 fatty acids diet in dogs with naturally occurring osteoarthritis. J. Anim. Physiol. 
Anim. Nutr. 97(5): 830-837.

Nabavi, S.F., Bilotto, S., Russo, G.L., Orhan, I.E., Habtemariam ,S., Daglia, M., Devi, K.P., Loizzo, M.R., Tundis, R. and Nabavi, S.M. (2015). Omega-3 polyunsaturated fatty acids and cancer: lessons learned from clinical trials. Cancer Metastasis Rev. 34(3): 359-380.

National Research Council. (2006). Nutrient Requirements of Dogs and Cats. Washington, D.C.: The National Academies Press.

Niyyat, M.R., Azizzadeh, M. and Khoshnegah, J. (2018). Effect of supplementation with omega-3 fatty acids, magnesium and zinc on canine behavioral disoeders: Results of a pilot study. Top. Companion Anim. M. doi: https://doi.org/10.1053/j.tcam.2018.08.006.

Olsson, N.U., Shoaf, S.E. and Salem, N. Jr. (1998). The effect of dietary polyunsatured fatty acids and alcohol on neutrasmitters levels in rat brain. Nutr. Neurosci. 1: 133140.

Padmanabhan, N. and Krishnamoorthy, G. (2017). "Therapeutic Relevance of Dietary Ratio of Polyunsaturated Fatty Acids N-6: N-3 in Canine Atopic Dermatitis". EC Nutrition 9.1: 36-50.

Pawlosky, R.J., Denkins, Y., Ward, G. and Salem, N. (1997). Retinal and brain accretion of long- chain polyunsaturated fatty acids in developing felines: the effects of corn oilbased maternal diets. Am. J. Clin. Nutr. 65: 465-72.

Popa, I., Pin, D. and Remoué, N. (2011). Analysis of epidermal lipids in normal and atopic dogs, before and after administration of an oral omega-6/omega-3 fatty acid feed supplement. A pilot study. Vet. Res. Commun. 35: 501-509.

Re, S., Zanoletti, M. and Emanuele, E. (2008). Aggressive dogs are characterized by low omega-3 polyunsaturated fatty acid status. Vet. Res. Commun. 32: 225-230.

Rooke, J., Shao, C. and Speake, B. (2001). Effects of feeding tuna oil on the lipid composition of pig spermatozoa and in vitro characteristics of semen. Reproduction 121: 315-322.

Roush, J.K., Cross, A.R. and Renberg, W.C. (2010b). Evaluation of the effects of dietary supplementation with fish oil omega-3 fatty acids on weight bearing in dogs with osteoarthritis. J. Am. Vet. Med. Assoc. 236: $67-73$.

Roush, J.K., Dodd, C.E. and Fritsch, D.A. (2010a). Multicenter veterinary practice assessment of the effects of omega-3 fatty acids on osteoarthritis in dogs. J. Am. Vet. Med. Assoc. 236: 59-66.

Safarinejad, M.R. and Safarinejad, S. (2012). The roles of omega-3 and omega- 6 fatty acids in idiopathic male infertility. Asian J. Androl. 14: 514-515.

Sagols, E., Priymenko, N. (2011). Oxidative stress in dog with heart failure: The role of dietary fatty acids and antioxidants. Vet. Med. Int. 2011: 1-5.

Schlanger, S., Shinitzky, M. and Yam, D. (2002). Diet enriched with omega-3 fatty acids alleviates convulsion symptoms in epilepsy patients. Epilepsia 43(1): 103-104.

Scorza, F.A., Cavalheiro, E.A., Arida, R.M., Terra, V.C., Scorza, C.A., Ribeiro, M.O. and Cysneiros, R.M. (2009). Positive impact of omega-3 fatty acid supplementation in a dog with drugresistant epilepsy: A case study. Epilepsy Behav. 15: 527-528.

Scott, D.W. (1995). What's new on canine dermatology? In: Proceedings of $12^{\text {th }}$ Annual Congress of European Society of Veterinary Dermatology, Barcelona, Spain, Pp. 163-65.

Sentürk, S. and Yalçin, E. (2003). Hypocholesterolaemia in dogs with dominance aggression. J. Vet. Med. A Physiol. Pathol. Clin. Med. 50: 339-342.

Simona, R., Zanoletti, M. and Emanuele E. (2008). Aggressive dogs are characterized by low omega-3 poluynsaturated fatty acid status. Vet. Res. Commun. 32(3): 225-30.

Smith, C.E., Freeman, L.M., Rush, J.E., Cunningham, S.M. and Biourge, V. (2007). Omega-3 FA in Boxer dogs with Arrythmogenic Right Ventricular Cardiomyopathy. J. Vet. Intern. Med. 21: 265-273.

Stice, S.A. (2019). Omega Fatty Acids. In: Gupta, R., Srivastava, A., Lall, R. (eds) Nutraceuticals in Veterinary Medicine. Springer, Cham. 
Surai, P., Noble, R., Sparks, N. and Speake, B. (2000). Effect of long-term supplementation with arachidonic or docosahexaenoic acids on sperm production in the broiler chicken. J. Reprod. Fertil. 120: 257-264.

Torrejon, C., Jung, U.J. and Deckelbaum, R.J. (2007). N- 3 Fatty acids and cardiovascular disease: actions and molecular mechanisms. Prostaglandins Leukot. Essent. Fatty Acids 77: 319-26.

Valle, P.G., Veado, J.C.C., Anjos, T.M., Tassini, L.E.S., Ferreira, L.F.L. and Lucas, L.D.F. (2015). Effect of the association of diet, omega-three, and antioxidants in dogs with chronic kidney disease. Semin. Ciênc. Agrár. 36(5): 3161-3172.

Van den Berg, L., Kwant, L., Hestand, M.S., Van Oost, B.A. and Leegwater, P.A. (2005). Structure and variation of three canine genes involved in serotonin binding and transport: the serotonin receptor $1 \mathrm{~A}$ gene (htr1A), serotonin receptor $2 \mathrm{~A}$ gene (htr2A), and serotonin transporter gene (slc6A4). J. Hered. 96: 786-796.

Voith, V.L., Wright, J.C. and Danneman, P.J. (1992). Is there a relationship between canine behavior problems and spoiling activities, anthropomorphism, and obedience training? Appl. Anim. Behav. Sci. 34: 263-272.

Wang, C., Harris, W.S. and Chung, M. (2006). N3 Fatty acids from fish or fish-oil supplements, but not $\alpha$-linolenic acid, benefit cardiovascular disease outcomes in primary and secondary prevention studies: a systematic review. Am. J. Clin. Nutr. 84: 517.

Wathes, D.C., Abayasekara, D.R. and Aitken, R.J. (2007). Polyunsaturated fatty acids in male and female reproduction. Biol. Reprod. 77: 190-201.

Watson, T.D.G. (1998). Nutrition and Disease. J. Nutr. 128: 2783-89.

Wells, D.L. and Hepper, P.G. (2000). Prevalence of behavior problems reported by owners of dogs purchased from an animal rescue shelter. Appl. Anim. Behav. Sci. 69: 55-65.

Whelan, J. and Fritsche, K. (2013). Linoleic Acid. Adv. Nutr. 4: 311-312.

Yeste, M., Barrera, X., Coll, D. and Bonet, S. (2011). The effects on boar sperm quality of dietary supplementation with omega-3 polyunsaturated fatty acids differ among porcine breeds. Theriogenology 76: 184196.

Zicker, S.C., Jewell, D.E, Yamka, R.M. and Milgram, N.W. (2012). Evaluation of cognitive learning, memory, psychomotor, immunologic, and retinal functions in healthy puppies fed foods fortified with docosahexaenoic acid-rich fish oil from 8 to 52 weeks of age. J. Am. Vet. Med. Assoc. 241: 583-94.

\section{How to cite this article:}

Haneet Kaur, Ankita Singla, Snehdeep Singh, Sandip Shilwant and Ravneet Kaur. 2020. Role of Omega-3 Fatty Acids in Canine Health: A Review. Int.J.Curr.Microbiol.App.Sci. 9(03): 2283-2293. doi: https://doi.org/10.20546/ijcmas.2020.903.259 